\title{
Democratizar a escola através do currículo: em busca de uma nova utopia... ${ }^{1}$
}

\author{
José Carlos Morgado*
}

\section{Resumo}

Partindo da ideia de que é muito dificil construir uma escola inclusiva no seio de uma sociedade de progresso e abundância, mas onde pululam desigualdades, se acentua a precarização da juventude e proliferam casos de exclusão, importa questionar até que ponto a escola, conjugando o melhor do passado com as mudanças do presente e os avanços do futuro, poderá contribuir para inverter esta situação. Tal ensejo obriga-nos a repensar a missão social da escola e a pugnar para que o currículo, que ai se desenvolve, se assuma como um espaço coletivo de compromissos, um estímulo à participação, uma oportunidade de reflexão e uma forma de desenvolver uma verdadeira educação moral, onde os valores se assumam como eixos estruturantes de uma sociedade mais justa, mais solidária e mais democrática. Os professores assumem, neste processo, responsabilidades acrescidas, já que das suas capacidades intelectuais e das virtudes do seu carácter depende, em muito, da excelência do ato pedagógico. É, pois, em torno destes pressupostos que pretendo, ao longo deste texto, interpelar a escola e o currículo em busca de uma nova utopia.

Palavras chave: Currículo. Troca de práticas. Democratização da escola.

\section{Introdução}

0 debate sobre a escola pública continua bem vivo, o que demonstra a importância que a educação continua a merecer em termos políticos e sociais. Grande parte deste debate surge em consequência do recorrente escrutínio social a que a educação pública tem estado sujeita e que tem avivado quer a dificuldade de as escolas darem respostas expeditas e eficazes a muitas das solicitações e dos problemas com que se deparam, quer a progressiva perda de autoridade dos professores, quer, ainda, alguma falta de eficácia no trabalho desenvolvido por muitos deles.

A par dessa situação, têm vindo a ser implementadas políticas educativas e curriculares que, sob a égide da melhoria do serviço público de educação, pretendem

1 Este texto serviu de base à palestra de abertura do Fórum Currículo, escola e sociedade, inserido no $4^{\circ}$ Congresso Marista de Educação / Edição Internacional, sobre “Espaços, Tempos e Horizontes na Educação de Infâncias e Juventudes”, e que decorreu em São Paulo, Brasil, de 17 a 20 de julho de 2012.

* Doutorado em Educação; Professor no Departamento de Estudos Curriculares e Tecnologia Educativa, Instituto de Educação, Universidade do Minho; Investigador do Centro Investigação em Educação, Universidade do Minho.E-mail:jmorgado@ie.uminho.pt 
sobretudo redimensionar o sistema educativo em função de modelos alternativos de regulação e provisão do serviço educativo. Trata-se de um conjunto de medidas e mudanças políticas associadas a propósitos e valores próprios da economia e que, "em vez de curar", têm servido, essencialmente, para renovar o controlo oficial do sistema, introduzir "novas formas de incerteza e insegurança" e gerar "sentimentos de heteronomia profissional" (SANCHES, 2009, p. 128). Fundadas na base de lógicas hierarquizantes e na procura imediata de niveis de qualidade mais elevados, as atuais políticas educativas geraram uma clara obsessão normativa e uma "estandardização insensivel" (HARGREAVES, 2003, p. 118), acabando por veicular perspetivas mais tecnicistas de ensino e por tentar relegar os professores para funções meramente executivas.

Se aos aspetos referidos associarmos a torrente de mudanças e transformações que perpassa a sociedade contemporânea, com reflexos não só à nossa volta mas também no nosso interior, isto é, na forma como cada um de nós concebe e representa o mundo (LÉVY, 1993), facilmente se compreende a profusão de significações que tem vindo a ser gerada em torno da educação e o permanente questionamento da escola pública, no sentido de a interpelar sobre a concretização, ou não, dos propósitos que subjazem aos seus princípios estruturantes - em particular no que se refere à igualdade de oportunidades no acesso e sucesso escolares e à efetiva integração social e profissional dos indivíduos que a frequentam - e sobre a qualidade do serviço que presta.

Tendo plena consciência de que é muito difícil construir uma escola inclusiva no seio de uma sociedade de progresso e abundância, mas onde pululam desigualdades a vários níveis, se acentua a precarização da juventude e proliferam casos de exclusão, importa questionar até que ponto a escola, conjugando o melhor do passado com as mudanças do presente e os avanços do futuro, poderá contribuir para inverter esta situação. É esse o principal propósito deste texto, ao longo do qual procuramos repensar a missão social da escola e justificar porque é que defendemos que o currículo que aí se desenvolve deve ser assumido como um espaço coletivo de compromissos, um estímulo à participação, uma oportunidade de reflexão e uma forma de desenvolver uma verdadeira educação moral, onde os valores se assumam como eixos estruturantes de uma sociedade mais justa, mais solidária e mais democrática. Alertamos, ainda, para as responsabilidades acrescidas que os professores assumem nesse processo, já que das suas capacidades intelectuais e das virtudes do seu carácter depende, em muito, a excelência do ato pedagógico.

Num momento em que o futuro nos apresenta desafios radicalmente diferentes dos que enfrentámos até agora, somos, por isso, compelidos, enquanto professores, a reencontrar-nos connosco e com o mundo, a repensar as nossas prioridades, a desenvolver novas formas de ensino e aprendizagem e a optar por caminhos que 
transformem a escola num local aprazivel numa verdadeira referência social e cultural. Dito de outra forma, somos compelidos a interpelar a escola e o currículo em busca de uma nova utopia.

É sobre a possibilidade de mudar a escola a partir do currículo que pretendo refletir ao longo deste texto, embora o espaço de que disponho não permita uma abordagem tão exaustiva como seria desejável. Para o efeito, estruturei o presente texto em torno de quatro eixos de análise:

(1) 0 primeiro, que intitulei "A vertigem da mudança e seus reflexos na educação", onde faço referência aos principais processos de mudança social e aos avanços políticos e económicos registados nos últimos anos, bem como aos seus reflexos no campo da educação, com particular incidência no que aqui designo por "tirania da inevitabilidade";

(2) Na segunda dimensão de análise, intitulada "A necessidade de (re)democratizar a escola", inventario alguns aspetos que, em meu entender, têm contribuido para o atual impasse em que se encontram as instituições educativas e que nos "obrigam" a (re)pensar a escola, na tentativa de, por um lado, compreender os processos de mutação a que tem estado sujeita, em particular os que decorrem da sua massificação, e, por outro lado, engendrar alternativas que permitam idealizar e concretizar processos de ensino e de aprendizagem mais consonantes com as necessidades da maioria dos jovens que a frequentam;

(3) No terceiro eixo de análise, que designo "No trilho de um currículo democrático", pretendo chamar a atenção para a necessidade de abandonar uma conceção mais tradicionalista de currículo - isto é, como um conjunto de objetivos, de conteúdos e de resultados previamente definidos - em prol de uma conceção de currículo idealizada como conjunto de aprendizagens socialmente reconhecidas e que todos os alunos devem construir, apelando assim à sua participação nesse processo, bem como ao seu desenvolvimento pessoal e social;

(4) Por fim, no último eixo de análise, referenciado como "Desafios políticos, pedagógicos e curriculares", elenco alguns aspetos que, em meu entender, se revelam fundamentais quer para recolocar a educação no lugar que merece, quer para revalorizar a profissão docente e devolver aos professores o protagonismo e o reconhecimento que merecem (e já tiveram) por parte da sociedade.

\section{A vertigem da mudança e seus reflexos na educação}

Se observarmos as mudanças que ocorreram nas últimas quatro ou cinco décadas nos paises mais desenvolvidos, facilmente constatamos que somos espetadores de um conjunto de transformações e acontecimentos inovadores de tal ordem, que não encontramos uma outra etapa na história que tenha obrigado as pessoas a tanto esforço de acomodação e adaptação a novas formas de vida (ESTEVE, 2009). 
Em poucos anos, assistimos a um enorme progresso científico e a uma autêntica revolução no campo tecnológico, em particular no domínio das tecnologias da informação e da comunicação (TIC), com reflexos tanto ao nivel da produção de instrumentos e técnicas cada vez mais sofisticados, como do volume de informação e conhecimento disponivel, aspetos que, apesar de terem contribuído para melhorar a qualidade de vida das pessoas, acabaram por interferir não só na vida quotidiana e no comportamento de cada indivíduo, mas também na forma como se organizam, reestruturam e/ou operacionalizam as próprias dinâmicas sociais. Para Alain Touraine (2005) estas transformações, que contribuíram para transfigurar o paradigma social que vinha imperando até então e para reconfigurar a realidade em que vivemos, materializam a rutura dos principais laços sociais, a perda de centralidade de muitas instituições e/ou agências socializadoras e a (re)valorização do ator social, seus interesses, expectativas e interações, alimentando tendências claramente individualistas em detrimento de preocupações de cariz mais coletivo.

Na opinião de Manuel Castells (2000), esta vaga de transformações, que se iniciou com a crise económica que eclodiu no início dos anos setenta, do século passado - crise do petróleo -, é concomitante com a afirmação de um novo paradigma - paradigma da tecnologia e da informação - e o abandono dos padrões de comportamento e das estruturas de produção herdadas da sociedade industrial e que se vinham mostrando cada vez mais inoperantes. Esta mudança paradigmática terá dado um forte impulso à globalização e terá estado na base da emergência da sociedade do conhecimento, um modelo de sociedade onde a criação, o processamento e a utilização da informação e do conhecimento se revelam fontes fundamentais de produtividade e produção de riqueza. Assim se compreende que as novas tecnologias e o conhecimento se tenham convertido no motor da economia, dando lugar ao que vários autores designam como economia do conhecimento, pois qualquer sistema de produção que não se estruture na base de uma renovação tecnológica contínua e de uma constante inovação ficará rapidamente obsoleto (ESTEVE, 2009).

Em termos económicos, a passagem de uma ordem estável e previsível, fundada no uso da razão e no respeito pela verdade transmissivel, para um tempo pejado de mudanças e incertezas fica também marcada pelo protagonismo que assumem tanto a internacionalização da produção, como a globalização dos mercados, vistas como imperativos para a captação de recursos, para garantir a venda e a troca de produtos e para a melhoria da situação financeira de cada pais. Trata-se, como assegura Puelles Benitez (2009), da afirmação de uma nova fase do capitalismo que, beneficiando do aumento de produtividade que as novas tecnologias da informação e do conhecimento propiciam, passa a estruturar-se em torno de novos referentes, dos quais se salientam o livre movimento de capitais, a diminuição do custo da mão-de-obra, o aumento exponencial do desemprego, a expansão do setor de serviços em detrimento dos setores agrícola e da indústria, a redução do poder 
reivindicativo dos trabalhadores e dos sindicatos e o aprofundamento do abismo económico, financeiro e tecnológico entre os paises mais desenvolvidos, inseridos na economia do conhecimento, e os paises subdesenvolvidos, alheios a ela.

Este cenário de mudança teve reflexos significativos nos diversos quadrantes que configuram a realidade contemporânea, sendo de salientar três aspetos que considero cruciais pelos efeitos que produziram no terreno da educação.

Em primeiro lugar, o facto de, na maioria dos paises tecnologicamente mais desenvolvidos, as ideologias socioeconómicas perderem relevância a favor da ideologia do livre mercado, viabilizando a emergência de um modelo de sociedade que procura nortearse por valores e práticas relacionados com produtividade, competitividade, individualismo, meritocracia, excelência, eficiência e eficácia. Não são esses os conceitos que têm marcado presença nos atuais discursos políticos e educativos? Não são esses os referentes que têm conformado as tentativas de reforma imprimidas no domínio da educação?

Em segundo lugar, a perda de protagonismo do Estado, cuja fragilidade ao nivel do seu poder intervencionista permitiu a ascensão do mercado, na tentativa de substituí-lo como força reguladora da sociedade (TOURAINE, 1999). Uma situação facilitada pelo próprio Estado ao eleger "a racionalidade econômica, a otimização e a eficiência como elementos nucleares" e ao desenvolver programas de modernização que tomaram como "referência privilegiada a atividade económica, a organização produtiva e o mercado, exportando a ideia de empresa para o seio da administração pública" (LIMA, 2002, p. 21). Foram estas opções que estiveram na base da modificação das relações entre o Estado e a sociedade, mudança que culmina na "passagem do modelo de controlo estatal para o modelo de supervisão estatal" (AMARAL; MAGALHÃES, 2000, p. 11), isto é, para lógicas de ação em que a "regulação burocrática", decorrente do "exercício do poder pela autoridade, hierarquia, regulamentação formal", cede espaço à afirmação de uma "regulação de tipo mercantil", baseada no "exercício do poder pela influência, ajustamento mútuo, carácter difuso e informal das regras e das relações" (AFONSO, 2003, p. 51).

Por fim, o facto de nos dias de hoje se tentar, em termos culturais, redefinir as relações com o passado, o presente e o futuro. Vivemos numa fase da Humanidade em que, pelos motivos expendidos mais atrás, o passado surge cada vez mais associado ao obsoleto e o futuro se configura como incerto e ameaçador, o que nos compele a concentrar-nos no presente, numa clara tendência de focalizar tudo no curto prazo, no aqui e agora (TEDESCO, 2010). Trata-se do que designo por tirania da inevitabilidade para denunciar uma certa ideologia que, escudando-se nas incertezas que perpassam os tempos atuais, na torrente de mudanças com que nos confrontamos diariamente e nos inúmeros e intensos progressos científicos, tecnológicos e económicos mais recentes, gera em cada um de nós uma certa sensação de impotência para alterar o rumo dos 
factos, compelindo-nos à inércia e à aceitação passiva do rumo dos acontecimentos. Na opinião de Daniel Innerarity (2009, p. 53), essa situação resulta do facto de a nossa relação com o tempo se ter desregulado, "o que dificulta a nossa projeção do futuro e facilita a nossa absorção pela urgência do presente".

Trata-se, no fundo, da afirmação de uma ideologia que, baseada numa desregulação económica, tenta legitimar uma nova forma de racionalização das práticas sociais e evidenciar a supremacia dos valores económicos, científicos e tecnológicos sobre os valores de indole cultural, social e moral, procurando erigi-la como "cosmovisão totalizadora da realidade" (GIMENO, 2005, p. 131). Em idêntica linha de pensamento, Pierre Bourdieu (1992) considera que se trata apenas de impor uma "visão dominante" fazendo-a passar como inevitável, com o objetivo de desfalecer as conceções divergentes e de eliminar qualquer tentativa de resistência.

Esta alucinação pelo imediato tem tido reflexos negativos no campo da educação, tradicionalmente concebida como responsável pela transmissão do património cultural às novas gerações e pela conceção de um determinado projeto futuro, que se vê despojada de grande parte do seu sentido (BOURDIEU,1992). Uma perda de sentido que se reflete também no trabalho desenvolvido pelos docentes que, por verem definhar duas das suas principais funções - a transmissão da herança cultural e a formação dos cidadãos do futuro -, se sentem desarmados e cada vez mais impotentes para contrariar esta situação e recuperar o protagonismo perdido.

Impõe-se, neste momento, levantar as seguintes questões:

- Não é isto que está a passar-se nas nossas escolas?

- Não têm os professores, por contingências de vária ordem, sido compelidos a capitalizar os ensinamentos e experiências do passado mais para a consecução das prioridades do tempo presente, do que para a idealização e concretização de projetos e investimentos futuros?

- Dito de outra forma, esta incapacidade de configurar o futuro não estará a contribuir para ostracizar os ideais educativos e a missão social da escola, protelando a construção de uma escola verdadeiramente inclusiva, capaz de propiciar aprendizagens de qualidade a todos os que a frequentam, independentemente das suas condições de partida?

- Dito, ainda, de outra forma: Que efeitos têm produzido o acréscimo de formação e o aumento da escolaridade na democratização das oportunidades dos indivíduos?

\section{A necessidade de (re)democratizar a escola}

Se olharmos para a história da educação, constatamos que, ao longo de muitas décadas, a educação foi sendo idealizada como fator central do desenvolvimento, 
de combate às injustiças e de promoção do bem-estar dos indivíduos. Daí a escola ser tida como um elemento imprescindivel para o progresso de cada país e, ao mesmo tempo, como um meio propício para desenvolver o pensamento crítico dos indivíduos, indispensável numa lógica de transformação da própria sociedade. Assim se justifica que o debate sobre a escola ou, mais concretamente, sobre a "crise da escola" continue na ordem do dia, o que demonstra, por um lado, a importância que a educação continua a merecer no imaginário social e, por outro, a clara dificuldade de compreender as mudanças que sofreu nos últimos anos e as que precisa concretizar para conseguir dar resposta aos desafios com que se confronta.

$\mathrm{Na}$ verdade, a complexidade do tempo presente, a diversidade de solicitações que hoje se colocam às escolas e a carência de respostas eficazes contribuíram para tornar visivel uma certa inadequação do sistema educativo, quer para formar cidadãos capazes de responder à pluralidade de desafios com que atualmente se deparam, quer para atenuar algumas assimetrias e desigualdades que continuam a proliferar socialmente. Assim se compreende a atenção que a educação tem merecido por parte do poder político e se justificam as sucessivas reformas que foram sendo desencadeadas, procurando reabilitar uma escola que, em muitos casos, tem alienado as suas capacidades de ação a favor de posturas mais reativas.

Portugal não foge a esse cenário. As mudanças políticas dos últimos anos e as reformas implementadas não corresponderam às tão almejadas melhorias nem tampouco à igualização das oportunidades sociais dos cidadãos. Temos hoje um volume significativo de qualificações que ombreia com taxas de desemprego até há bem pouco tempo inimagináveis, o que comprova que "as promessas de que mais escola traria mais desenvolvimento, mais igualdade e maior mobilidade social nem sempre se confirmaram" (SOEIRO, 2008).

Na opinião de Rui Canário (2005, p. 84), "o efeito conjugado da expansão dos sistemas escolares e das mutações no mundo do trabalho tende a acentuar a discrepância entre o aumento da produção de diplomas pela escola e a rarefação de empregos correspondentes", conduzindo não só à inevitável "desvalorização dos diplomas escolares", mas também à diminuição da sua rentabilidade no mercado de trabalho, com o consequente aumento dos "níveis de frustração de uma maioria social que mantém com a escola uma relação fundada na "utilidade" dos estudos, em termos da obtenção de um estatuto social e rendimentos elevados". Talvez por isso, os sentimentos dominantes em relação à escola sejam hoje de desconfiança e de incerteza.

Por outro lado, se "a massificação do ensino foi um processo extraordinário", a verdade é que embora resolvendo o problema do acesso não conseguiu, ainda, resolver o problema do sucesso educativo, o que, na opinião de José Soeiro (2008), vem comprovar que "o acesso à escola, por si só, não consegue romper o ciclo vicioso da pobreza, porque não garante a todos as mesmas condições de sucesso". 
Dito de outra forma, "a escola massificou-se sem se democratizar completamente".

Quando isto acontece, a escola acaba, inevitavelmente, por contribuir mais para a reprodução social e para acentuar as desigualdades do que para incluir e emancipar os individuos que a frequentam.

A escola fabrica várias formas de exclusão. Não deixa entrar os que estão fora e esse é o problema do acesso. Põe fora os que estão dentro - e ai estamos perante o drama do insucesso escolar e do abandono. Exclui incluindo - a forma escolar é em si uniformizadora e adversa à diversidade. $E$, num certo sentido, a inclusão na escola deixou de fazer sentido, porque é difícil perceber para que é que precisamos de lá estar. A cada um destes problemas - 0 acesso, o sucesso, a diversidade dos públicos escolares e o sentido do trabalho escolar - nós só podemos responder com uma escolha: mais e melhor democracia. (SOEIRO, 2008).

Os factos que acabamos de expender permitem-nos concluir que o diagnóstico sobre a situação atual da escola é sombrio. Dai a necessidade de problematizar o seu futuro ou, como assevera Rui Canário (2005, p. 87), de "agir estrategicamente, no presente, para que o futuro possa ser o resultado de uma escolha e não a consequência de um destino".

É nessa ordem de ideias que se torna imprescindivel (re)democratizar a escola, o que requer que se faça uma crítica séria sobre a situação em que se encontra e se envolvam os distintos agentes educativos numa efetiva reinvenção e reedificação da escola do futuro. Na esteira do que é proposto pelo autor (CANÁRI0, p. 87-88), tal processo deverá nortear-se por três finalidades fundamentais:

a) construir uma escola onde se aprenda pelo trabalho e não para o trabalho - o que requer que, em termos funcionais, a educação escolar deixe de se subordinar à racionalidade económica; para que isso aconteça, é necessário que o aluno se assuma como "produtor", deixando de basear a sua aprendizagem na memorização, e passe da "repetição de informação para a produção de saber";

b) fazer da escola um sítio onde se desenvolva o gosto pelo ato intelectual de aprender - mais do que a valorização utilitarista dos saberes, é necessário que sirvam para "ler, compreender e intervir no mundo;

c) transformar a escola num local em que se ganhe gosto pela política - isto é, onde se viva a democracia, se exerça o direito à palavra, sobretudo para pensar e intervir no mundo, e se aprenda a ser intolerante com as injustiças.

Para que isso seja possível, é necessário que se idealize e desenvolva um currículo democrático na escola. 


\section{No trilho de um currículo democrático}

À semelhança do que se passa na sociedade, onde a noção de democracia é constantemente invocada como princípio inviolável mas, raramente definida e concretizada como prática social ou cultural (GOODMAN, 2001), também em muitas das nossas escolas os processos de ensino-aprendizagem se restringem, em grande parte, à apropriação pelos alunos dos saberes escolares necessários à construção do seu património intelectual. Não deixando de reconhecer a importância dessa dimensão, é necessário propiciar aos alunos aprendizagens nos domínios das capacidades e das competências, apetrechando-os para utilizarem esses conhecimentos na sua vida diária, bem como momentos de reflexão, de partilha e de trabalho em equipa, capazes de contribuirem para o debate, para o confronto de distintas formas de ver e idealizar o mundo, para aprender a ouvir, respeitar e compreender o outro, enfim, para desenvolver valores, atitudes e procedimentos mais consonantes com a vida em democracia².

No fundo, trata-se de idealizar uma educação do futuro, consubstanciada por um ensino "centrado na condição humana" (MORIN, 2001, p. 57). Uma educação que eleja a pessoa como centro de toda a ação educativa e faça da inclusão, da solidariedade, da compreensão, da cidadania, da liberdade, da democracia e do respeito pela natureza e pelos outros imperativos inadiáveis e essenciais para compreender melhor o mundo.

Para que isso seja possivel, é necessário perfilhar uma conceção de currículo substancialmente diferente da que tem imperado nos sistemas de ensino. Em vez de um plano previamente definido e estruturado, de forma a ser implementado na prática, o currículo deve resultar de uma "construção participada" e de "uma partilha assumida de poderes e de responsabilidades" (MORGADO, 2002, p. 1035), permitindo assim que os vários intervenientes no processo educativo se sintam corresponsabilizados na (re)formulação das políticas de ensino e na conceção e realização de um projeto formativo comum.

É nessa ordem de ideias que faz todo o sentido falar de currículo como projeto e como prática participada, isto é, de um currículo democrático. Enquanto expressão da função socializadora e cultural da escola, o currículo é uma prática que se expressa através de comportamentos diversos e onde se estabelece um diálogo entre os vários agentes sociais, técnicos, estudantes, professores e demais elementos da comunidade educativa (GIMENO, 1988). Ao retratar uma confluência de interesses e forças que pululam no seio do sistema

\footnotetext{
Convém lembrar que, na opinião de Jess Goodman (2001), quando o currículo escolar se circunscreve, essencialmente, ao desenvolvimento de destrezas básicas - tais como leitura, escrita e aritmética - impede que as escolas se transformem em lugares onde os estudantes aprendam a perguntar, a observar, a explorar criticamente e a desenvolver a curiosidade sobre o mundo em que vivem. Além disso, não é dada voz às suas ideias, às suas experiências e aos seus anseios, o que facilita que se gere o conformismo e que as escolas se transformem em meras academias de ensino profissional.
} 
educativo, o currículo acaba por ser o reflexo dos conflitos de interesses e dos valores dominantes que determinam os processos educativos na sociedade. Estamos assim na presença de um terreno em que se espraiam e misturam outros campos e onde convergem diversos elementos que, numa permanente simbiose, configuram a realidade escolar.

Ao ser por excelência um instrumento da prática pedagógica, o currículo relaciona-se intimamente com a profissionalidade docente, entrecruza componentes e determinações pedagógicas, políticas, administrativas e de inovação, em suma, é um ponto central de referência para a melhoria da qualidade de ensino, das práticas docentes e da renovação da instituição escolar em geral. 0 currículo é, assim, entendido como um complexo projeto social, com múltiplas expressões e com uma dinâmica própria, construída no tempo e sob certas condições.

Assim se compreende que Amador Guarro $(2002$, p. 21) afirme que só numa sociedade onde a democracia seja encarada como algo que está para além do mero sistema político, isto é, como um modo de vida norteado por valores comuns e democráticos, e com um sistema educativo que se comprometa a transferir para a escola esses valores, é possivel construir um currículo democrático. Aliás, nenhum sistema educativo "pode ser mais virtuoso do que a sociedade que lhe confere a sua legitimidade e os seus recursos" (PERRENOUD, 2002, p. 13). Dai que um currículo democrático seja, por isso, algo que ultrapassa amplamente os limites estritos das escolas e as responsabilidades isoladas dos professores. Pensar e construir um currículo democrático não é um assunto exclusivamente escolar, é um assunto que envolve também o social e o político (MUÑOZ, 2006).

Mas, como se constrói um currículo democrático?

Na opinião de Amador Guarro (2002), existem três pressupostos essenciais para se poder conceber e desenvolver um currículo democrático: uma sociedade democrática, um sistema educativo democrático e uma escola democrática. Ora, sendo o currículo um empreendimento negociado e partilhado, fundado num processo permanente de (des)construção do conhecimento e num conjunto de práticas que procuram estabelecer a ponte entre a intenção e a realidade, a garantia dos pressupostos enunciados é uma condição essencial para que, com um mínimo de coerência, se consigam preparar os alunos para serem cidadãos livres, ativos e críticos, membros solidários e interventivos numa sociedade que se quer livre e democrática.

Em idêntica linha de pensamento, Escudero Muñoz (2006) assegura que um currículo escolar só será democrático se for sustentado nos valores que reclamam a realização da justiça social através da escola e do currículo, o que leva, primeiro, a vinculá-lo ao imperativo social e ético de prover todas as pessoas de uma boa educação e, segundo, a assumir pela sociedade, pela escola e pelos docentes os compromissos que são precisos para garanti-lo com eficácia. Neste sentido, 
a construção de um currículo escolar que pretende ser democrático implica, necessariamente, participação e compromisso.

0 autor (MUÑOZ, 2006, p. 13) considera, ainda, que a participação e 0 compromisso, para além de suscitarem o debate no seio da instituição, devem envolver todos os agentes educativos em torno das seguintes questões:

- Que aprendizagens (intelectuais, pessoais, cívicas) devem ser pretendidas e concretizadas com todos os alunos?

- Que conteúdos devem ser selecionados e organizados de forma a atender aos contextos dos alunos e ao mundo que existe e que seria humano e justo construir?

- Que oportunidades, atividades, experiências e relações educativas devem ser orquestradas para que os alunos contem com possibilidades equitativas, adequadas aos seus ritmos e necessidades, de modo a poderem concretizar as aprendizagens consideradas essenciais?

- Que aspetos devem ser tidos em conta na avaliação, para que assuma, essencialmente, uma função formativa?

Em suma, a inserção do currículo escolar numa perspetiva de justiça social através da escola, a projeção de tal intento nos conteúdos do currículo desenvolvido com os alunos (currículo efetivo), a conceção do currículo como um empenho institucional (currículo de toda a escola ou agrupamento) e a adoção de uma perspetiva processual, que contemple a análise, a revisão, a crítica e a melhoria, são algumas das dimensões essenciais para caracterizar uma escola e um currículo democráticos (MUÑOZ, 2006).

Como acabamos de constatar, a qualidade democrática do currículo não depende só da sua conceção, mas também do modo como se desenvolve na prática. Assim sendo, 0 desenvolvimento do currículo deverá ser entendido como um processo que envolve a tomada de decisões e a participação de todos os agentes envolvidos, devendo o consenso ser o principal eixo estruturante de todo esse empreendimento (GUARRO, 2002).

É nesta ordem de ideias que o Projeto Curricular se pode revelar como garantia dessa participação, já que se trata de um empreendimento que tem a montante o Projeto Político-Pedagógico ${ }^{3}$ - documento de referência da identidade da escola e dos propósitos educativos que a mesma se propõe concretizar, decidido e elaborado pelos distintos agentes da comunidade escolar - e a jusante os processos de ensino-aprendizagem - aqui vistos como o culminar das intenções educativas que a escola persegue, envolvendo os principais interessados nesse processo, os professores e os alunos.

0 Projeto Curricular de Escola constitui-se, a este nivel, como um instrumento que concretiza as orientações curriculares de âmbito nacional em propostas globais

3 Em Portugal não se utiliza esta terminologia, sendo o Projeto Político Pedagógico o equivalente do Projeto educativo da Escola. 
de intervenção pedagógico-didática, adequadas a um contexto específico. Assumese, por isso, como um importante meio de decisão e deliberação curriculares ao nível da escola, na medida em que, sem descurar os planos curriculares, os programas e os propósitos educativos propostos a nível oficial, integra o "conjunto de decisões articuladas, partilhadas pela equipa docente de uma escola, tendentes a dotar de maior coerência a sua atuação" (CARMEN; ZABALA, 1991, p. 16 apud LEITE, 2003)4.

0 que se pode, ou se deve, então fazer para conseguir concretizar o que acabamos de referir?

\section{Desafios políticos, pedagógicos e curriculares}

Tal como referi no início da minha intervenção, e no seguimento do que vimos defendendo há vários $a_{n}{ }^{5}$, não podemos deixar de sinalizar quatro aspetos que consideramos necessários para transformar a escola atual e para que os professores se assumam como verdadeiros profissionais do ensino, contribuindo, assim, para que a educação pública se configure como um verdadeiro esteio na construção de uma sociedade democrática.

Em primeiro lugar, é preciso fazer da educação um desígnio nacional, o que requer a implementação de um projeto político que viabilize a universalidade do acesso à educação, garanta a igualdade de oportunidades e estimule o desenvolvimento pleno de todos os cidadãos, independentemente da sua origem ou classe social. Tal propósito só será possivel se forem definidas e implementadas politicas educativas e curriculares que concedam aos professores e demais agentes educativos oportunidades efetivas de participação e decisão curricular, reforçando a sua autonomia, que permitam uma efetiva adequação dos imperativos de âmbito nacional às caracteristicas e necessidades de cada contexto específico e que potenciem a introdução de inovação no sistema. Convém lembrar que um dos aspetos que mais tem contribuído para um certo descrédito que se tem instalado no seio das escolas e dos professores, e também da sociedade em geral, resulta do facto de a educação não ser assumida, tanto como se devia, uma prioridade nacional, uma situação para o que tem contribuído uma certa tendência de publicitar aquilo que de mais negativo acontece nas escolas, negligenciando tantas vezes as boas práticas que ai acontecem.

Em segundo lugar, é necessário adotar um novo conceito de currículo, entendido em simultâneo como projeto social e como processo deliberativo, o que requer flexibilização, articulação e uma efetiva autonomia curricular dos agentes que o concretizam, por oposição ao conceito de currículo que tem prevalecido em muitos sistemas de ensino, um currículo espartilhado, que sobrevaloriza os conhecimentos inscritos em áreas disciplinares, negligenciando uma série de outros conhecimentos e saberes transversais também importantes para o desenvolvimento integral de cada indivíduo (MORGADO, 2011).

4 Citados por Leite (2003, p. 115).

Cf. Morgado (2003, 2006, 2010, 2011). 
Em terceiro lugar, é preciso desenvolver estratégias que transformem a escola num lugar aprazivel para os alunos, de modo a que se sintam atraídos por ela e valorizem 0 que ali se faz, e se recorra a procedimentos que permitam que os alunos se sintam como sujeitos dos processos de ensino-aprendizagem e se impliquem num processo efetivo de produção de saberes (MORGADO, 2010). Para que isso seja viável é necessário, como lembra Rui Canário (2005, p. 88), "desalienar o trabalho escolar", o que requer que sejamos capazes de "pensar a escola a partir do não escolar", isto é, a partir de práticas e aprendizagens significativas que se realizam no seu exterior e se configuram como "portadoras de futuro".

Por fim, a necessidade de olhar para o futuro, tentando resistir ao que designei mais atrás por tirania da inevitabilidade. Trata-se de um exercício difícil, se tivermos em conta, como advoga Daniel Innerarity (2009), que é mais fácil lidar com a comodidade do presente do que com a incomodidade do futuro, que é algo que tem de ser imaginado antecipadamente e, por isso, algo incerto. Daí a sensação do presente ser mais poderoso, o que, com alguma frequência, nos tem desmotivado e inibido de programar e investir no futuro. A mudança acelerada cria desconforto, sobretudo quando sentimos que essa aceleração põe em causa a nossa capacidade de configurar um futuro com sentido e de forma mais significativa. Consequentemente, a nossa relação com o futuro torna-se mais complexa e menos ingénua e os nossos sentimentos são nem de esperança nem de projeto, mas sim de precaução e improvisação (INNERARITY, 2009).

Só que, numa sociedade de risco, como aquela em que vivemos atualmente, necessitamos de uma visão futurista e de instrumentos e práticas de antecipação, sem os quais o futuro nos pode escapar. E isso seria irremediável.

$\mathrm{Na}$ escola, tal como na família e na vida, nós somos aquilo que pensamos e aquilo que fazemos (SOEIRO, 2008). Mas somos, sobretudo, aquilo que fazemos para mudar. São, essencialmente, essa visão e essa vontade de mudança que consubstanciam a utopia a que me refiro no título da minha intervenção.

\section{Referências}

AFONSO, N. A regulação da educação na Europa: do Estado Educador ao controlo social da Escola Pública. In: BARROSO, J. (Org.). A Escola Pública: regulação, desregulação e privatização. Porto. Edições Asa: 2003, p. 49-78.

AMARAL, A.; MAGALHÃES, A. 0 conceito de stakeholder e o novo paradigma do ensino superior. Revista Portuguesa de Educação,[S.I.], v. 13, n. 2, p. 7-28, mar. 2000.

BENITEZ, M. P. Globalización, Neoliberalismo y Educación. Revista de la Asociación de Inspectores de Educación en España, Espanha, n. 11, nov. 2009. Disponivel em: < http://www.adide.org/revista/index.php?option=com_content\&t ask=sectionctid=16ctltemid=67>. Acesso em: 10 de jul. 2012. 
BOURDIEU, P. O poder simbólico. Rio de Janeiro: Bertrand, 1992.

CANÁRIO, R. O que é a escola?: um "olhar" sociológico. Porto: Porto Editora, 2005.

CASTELLS, M. La era de la información: la sociedad red. Madrid: Alianza, 2000. v. 1.

ESTEVE, J. M. Educación y Globalización. La Sociedad y la Economía del conocimiento. Revista de la Asociación de Inspectores de Educación en España, Espanha, n. 11, abr. 2009. Disponivel em: <http://www.adide.org/revista/index. php>. Acesso em: 10 jul. 2012.

GIMENO, J. El currículum: una reflexión sobre la práctica. Madrid: Morata, 1988.

. El significado y la función de la educación en la sociedad y cultura globalizadas. Revista de Educación, Madri, Espanha, n. 1, p. 121-142, set. 2005.

GOODMAN, J. La educación democrática en la escuela. Sevilla: Publicaciones M.C.E.P., 2001.

GUARRO, A. Currículum y democracia: por um cambio de la cultura escolar. Barcelona: Octaedro, 2002.

HARGREAVES, A. O Ensino na Sociedade do conhecimento: a educação na era da insegurança. Porto: Porto Editora, 2003.

INNERARITY, D. El futuro y sus enemigos. Barcelona: Paidós, 2009.

LEITE, C. Para uma escola curricularmente inteligente. Porto: Edições ASA, 2003.

LÉVI, P. As tecnologias da inteligência: o futuro do pensamento na era da informática. Rio de Janeiro: Editora 34, 1993.

LIMA, L. Modernização, racionalização e optimização: perspectivas neotaylorianas na organização e administração da educação. In: LIMA, L.; AFONSO, A. (Ed.). Reformas da Educação Pública: democratização, modernização, neoliberalismo. Porto: Edições Afrontamento, 2002, p. 17-32.

MORGADO, J. C. Autonomia curricular: coerência entre o local e o global. In: FERNANDES, M. et. al. O particular e o global no virar do milénio. Lisboa: Colibri, 2002, p. 1031-1040.

. Processos e práticas de (re)construção da autonomia curricular. 2003.

Tese (Doutorado)-Universidade do Ninho, Braga, 2003. Policopiado. 
MORGADO, J. C. Globalização e (re)organização do Ensino Superior:

perplexidades e desafios. Perspectiva, [S.I.], n. 24, v. 1, p. 205-228, nov.2006.

. Para um outro arquétipo de escola: a necessidade de mudar as políticas

e as práticas curriculares. Educação em Revista, Belo Horizonte, n. 26, v. 2, p. 1524, mar. 2010.

. Identidade e profissionalidade docente: sentidos e (im)possibilidades.

Ensaio: Avaliação e Políticas Públicas em Educação, Rio de Janeiro, n. 73, v. 19, p. 793-812, out./dez. 2011.

MORIN, E. Los siete saberes necesarios para la educación del futuro. Barcelona: Paidós, 2001.

MUÑOZ, J. E. La construcción de un currículo democrático y la cultura de colaboración del profesorado. Revista Cuatrimestral del Consejo Escolar del Estado, [S.I.], n. 3, p. 12-17, out. 2006.

PERRENOUD, P. A escola e a aprendizagem da democracia. Porto: Edições ASA, 2002.

SANCHES, M. F. C. "(in)sustentável leveza" da liderança dos professores em contextos de mudança: contrastes entre idealidade e realidade. In: (Org.). A escola como espaço social: leituras e olhares de professores e alunos. Porto: Porto Editora, 2009. p. 125-162.

SOEIRO, J. A defesa da escola pública e democrática: intervenção na sessão parlamentar de comemoração do 25 de Abril, 2008. [S.I.], 2008. Disponível em: <http://beparlamento.esquerda.net>. Acesso: 10 jul. 2012.

TEDESCO, J. C. Diez notas sobre el pacto social y educativo. Revista de la Asociación de Inspectores de Educación en España, Espanha, n. 12, mar. 2010. Disponivel em: <http://www.adide.org/revista/index.php>. Acesso em: 10 jul. 2012.

TOURAINE, A. Como sair do liberalismo?. Lisboa: Terramar, 1999. . Um novo paradigma: para compreender o mundo hoje. Lisboa: Instituto Piaget, 2005.

Recebido em: 19/12/2012 Aceito para publicação em: 16/04/2013 


\section{Democratizing the school through the curriculum: in search of a new utopia...}

\section{Abstract}

Starting from the idea that it is difficult to build an inclusive school within a society of progress and abundance but where inequalities abound, it is important to examine to what extent schools, combining the best of the past with the present changes and the future advancements, can play a role in reversing this situation. This opportunity makes us reconsider the social mission of schools and defend that the curriculum developed in schools assumes himself as a collective space of commitments, a stimulus to participation and a way to develop a true moral education, where the values assume themselves as structural axes of a fairer, more solidarity and more democratic society. Teachers assume greater responsibilities in this process, because the excellence of the pedagogical act depends largely of their intellectual abilities and of the virtues of its character. It is, therefore, around these assumptions that I intend to, throughout this text, challenge the school and the curriculum in search of a new utopia.

Keywords: Curriculum. Changing practices. School democratization.

\section{Democratizar la escuela a través del currículo: en busca de una nueva utopía \\ Resumen}

Partiendo de la idea de que es difícil construir una escuela inclusiva en el seno de una sociedad de progreso y abundancia pero donde proliferan desigualdades, importa cuestionar hasta qué punto la escuela, conjugando lo mejor del pasado con los cambios del presente y los avances del futuro, podrá contribuir para invertir esta situación. Tal empeño nos obliga a repensar la misión social de la escuela y a luchar para que el currículo que en ella se desarrolla se asuma como un espacio colectivo de compromisos, un estímulo a participar y una forma de desarrollar una verdadera educación moral, donde los valores se asuman como ejes estructurantes de una sociedad más justa, más solidaria y más democrática. Los profesores asumen en este proceso responsabilidades agregadas, ya que de sus capacidades intelectuales y de las virtudes de su carácter depende, en mucho, la excelencia del acto pedagógico. Es sobre estos presupuestos que pretendo, a lo largo de este texto, interpelar la escuela y el currículo en búsqueda de una nueva utopía.

Palabras-Claves: Currículo. Cambio de las prácticas. Democratización de la escuela. 